\title{
Heat Energy Harvesting untuk Sumber Listrik DC Skala Kecil
}

\author{
Arif Febriansyah Juwito* \\ Jurusan Teknik Elektronika, Politeknik Negeri Batam \\ arifjuwito@polibatam.ac.id
}

\begin{abstract}
Abstrak
Kondisi Provinsi Kepulauan Riau yang 95\% wilayahnya merupakan laut menyebabkan distribusi listrik pada pulaupulau kecil yang banyak tersebar di wilayah ini menjadi tidak merata. Kondisi panas matahari yang dihasilkan pada atap rumah nelayan pada siang hari dapat digunakan sebagai sumber listrik skala kecil dengan menggunakan piranti yang disebut dengan thermoelectric generator. Pada penelitian ini dibuat prototype penerima panas matahari yang selanjutnya dikonversi menjadi energy listrik. Prototype ini bekerja berdasarkan prinsip seeback, dimana perubahan panas di salah satu sisi dari thermoelectric generator menyebabkan terjadinya perbedaan suhu $(\Delta T)$ antara dua sisi yaitu sisi panas dan sisi dingin dari Thermoelectric Generator (TEG) sehingga menghasilkan beda potensial pada ujung - ujung kutub - p dan -n. Dari percobaan yang dilakukan pada prototype ini diperoleh hasil optimal dengan merangkai 20 TEG yang dihubungkan secara seri dan parallel, dihasilkan listrik dengan nilai tegangan sebesar 5 VDC dengan kondisi suhu permukaan heat collector sebesar $58,59^{\circ} \mathrm{C}$.
\end{abstract}

Kata Kunci: Thermoelectric Generator, Heat Collector, Energi listrik.

\begin{abstract}
The condition of Riau Islands Province which 95\% of its territory is the sea causes the distribution of electricity on small islands that are widely spread in this region becomes uneven. The solar heat conditions generated on the roof of a fisherman's house during the day can be used as a small-scale power source by using a device called a thermoelectric generator. In this research a prototype of solar thermal receiver is converted into electrical energy. The prototype works based on the seeback principle, where heat changes on one side of the thermoelectric generator cause a temperature difference ( $\triangle T$ ) between the two hot and cold sides of the Thermoelectric Generator (TEG) to produce a potential difference at the polar ends - $P$ and $-n$. From the experiments performed on this prototype obtained optimal results by assembling 20 TEG which connected in series and parallel, generated electricity with a voltage value of 5 VDC with surface temperature temperature of heat collector of 58,590 C.
\end{abstract}

Keywords: Thermoelectric Generator, Heat Collector, Electrical Energy 


\section{Pendahuluan}

Propinsi kepulauan riau merupakan salah satu provinsi di Indonesia yang sebagian besar wilayahnya terdiri dari lautan dengan perbandingan 95\% lautan dan 5\% daratan, sehingga daratan di provinsi kepulauan riau merupakan pulau-pulau kecil yang tersebar secara merata diseluruh wilayah di Provinsi ini [1].

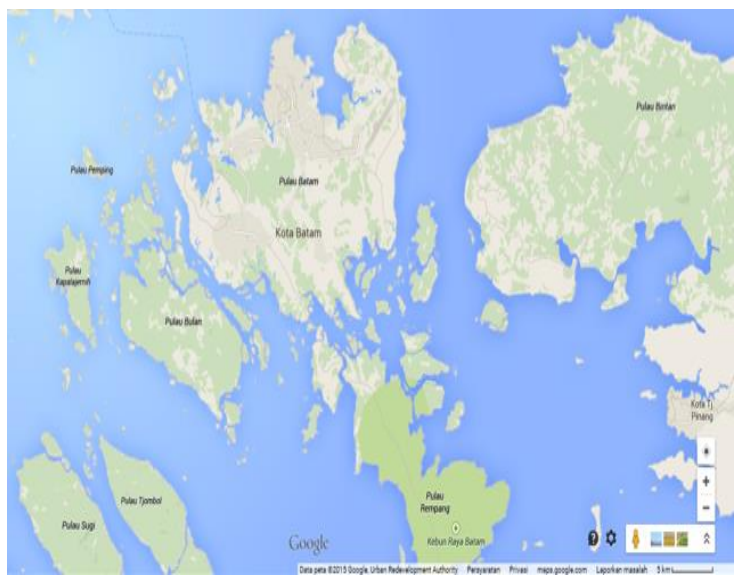

Gambar 1. Peta Kepulauan Riau

Secara geografis Provinsi Kepulauan Riau terletak di selat malaka yang berbatasan langsung dengan Negara Singapura dan Malaysia, kondisi ini menjadikan Provinsi Kepulauan Riau memiliki letak yang sangat strategis yang menjadikan provinsi ini salah satu tulang punggung perekonomian di Indonesia. Hal ini dapat dilihat dengan banyaknya industri manufaktur, galangan kapal, minyak dan gas yang berinvestasi di provinsi ini.

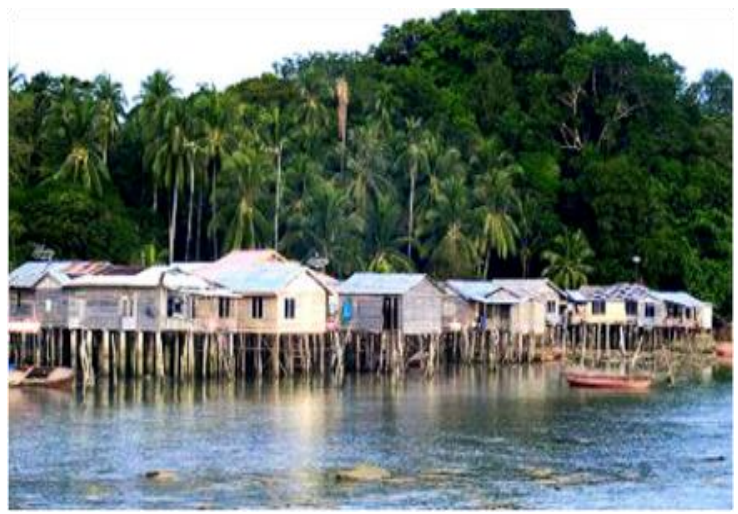

Gambar 2. Desa nelayan

Banyaknya industri yang ada di Provinsi Kepulauan Riau terutama di pulau Batam menyebabkan banyaknya energi listrik yang diperlukan untuk melayani beban listrik yang ada di kepulauan riau semakin besar dan cenderung bertambah setiap tahunnya [2]. Sedangkan untuk kondisi kelistrikan di pulau-pulau kecil disekitar pulau Batam dan Bintan sangat terisolasi hal ini dikarnakan jauhnya jarak antara pulau-pulau kecil dengan pulau Batam menyebabkan distribusi energi listrik tidak ekonomis, sehingga perlu dilakukan cara alternatif untuk untuk mengatasi permasalahan ini.

\section{Metode}

Penelitian ini dilakukan dengan memanfaatkan panas matahari pada atap rumah penduduk di desa nelayan kepulauan riau. Dimana suhu rata-rata ketika siang hari mencapai $50^{\circ} \mathrm{C}$. perbedaan suhu antara permukaan dan bawah atap $(\Delta t)$, digunakan sebagai penghasil listrik menggunakan Thermoelectric generator. Berdasarkan efek seeback, dimana koefisien seeback diperoleh menggunakan persamaan [3]:

$\alpha_{A B}=\frac{V}{\Delta T}$

dimana :

$$
\begin{array}{ll}
\alpha_{A B} & : \text { koefisien seeback } \\
V & : \text { tegangan } \\
\Delta T & : \text { perbedaan suhu }
\end{array}
$$

Gambar 3. Bagian thermoelectric generatorSistem

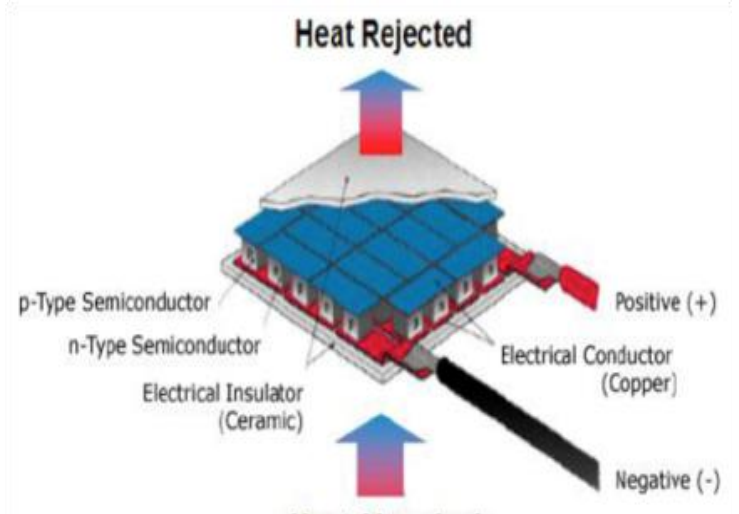

Heat Absorbed

energi harvesting yang dibuat pada penelitian ini memanfaatkan plat alumunium yang digunakan untuk merangkai komponen Thermo Electric Generator (TEG) yang terhubung secara seriparallel, yang kemudian plat alumunium tersebut dapat dipasang dibawah atap seng, atau dipaparkan langsung dibawah sinar matahari, sehingga langsung menyerap energi panas. Bentuk modul Heat Collector dapat dilihat pada gambar berikut:

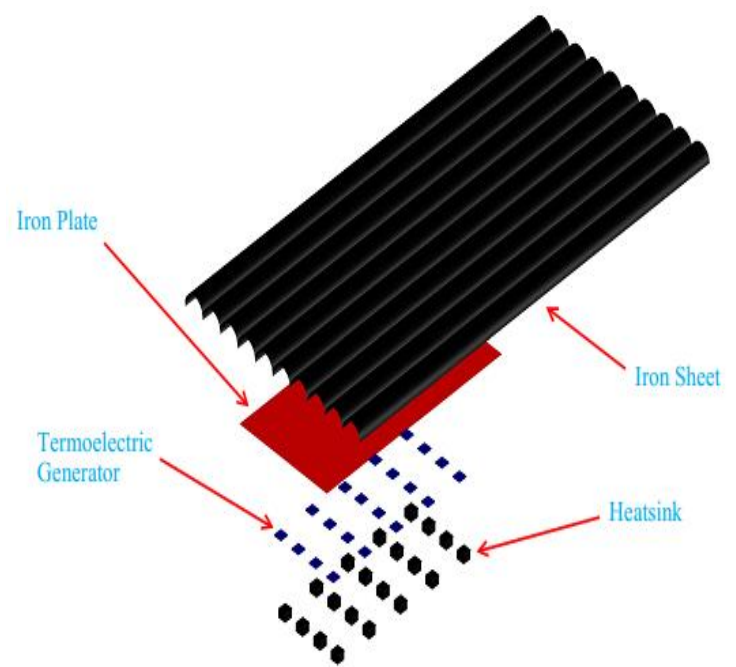

Gambar 4. Heat Collector (TEG Modul) 
Dikarnakan output dari Heat Collector sangat dipengaruhi oleh perbedaan suhu antara bagian panas dan bagian dingin dari TEG, maka untuk mengoptimalkan daya output pada collector, pada sisi bawah/ bagian dingin dari TEG dipasang heatsink sebagai media pelepas panas yang dihasilkan pada bagian dingin dari TEG dikarnakan pengaruh panas dari plat alumunium yang terkena sinar matahari.

Plat alumunium dipasang TEG dengan jumlah 20 buah, dimana dengan jumlah tersebut diharapkan dapat menghasilkan daya listrik yang optimal sesuai dengan suhu yang terukur pada heat collector.

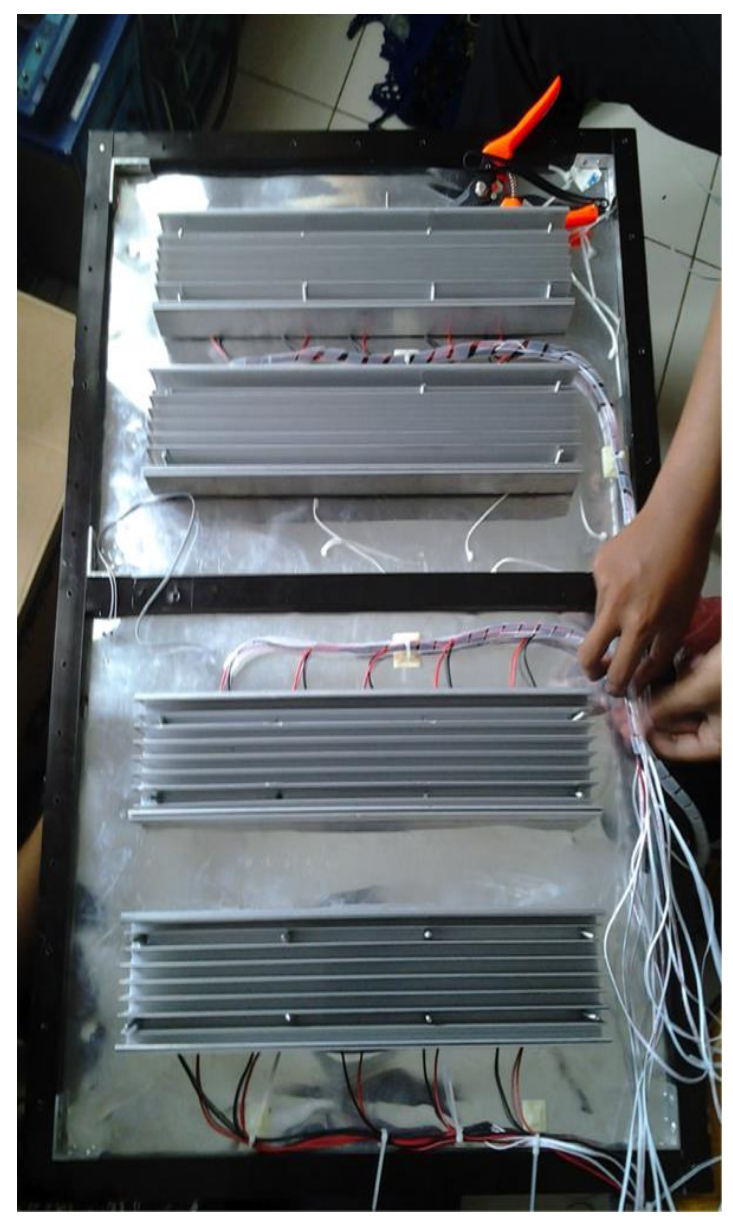

Gambar. 5. Pemasangan heatsink dan kabel

\section{Hasil dan Pembahasan}

Kondisi suhu puncak yang diperoleh dari pengukuran dalam kurun waktu antara pukul 11.00 hingga pukul 14.00 , rata-rata adalah $50^{\circ} \mathrm{C}$. Untuk mendapatkan tegangan output yang optimal dari sistem, Thermo Electric Generator (TEG) yang terpasang di collector, dirangkai dengan beberapa konfigurasi. Dimana output tegangan yang dihasilkan, diukur menggunakan alat monitoring tegangan dan suhu. Sehingga setiap perubahan suhu dan tegangan yang terjadi dapat disimpan dan digunakan sebagai bahan analisa.

Gambar 6. Pengujian dan pengambilan data

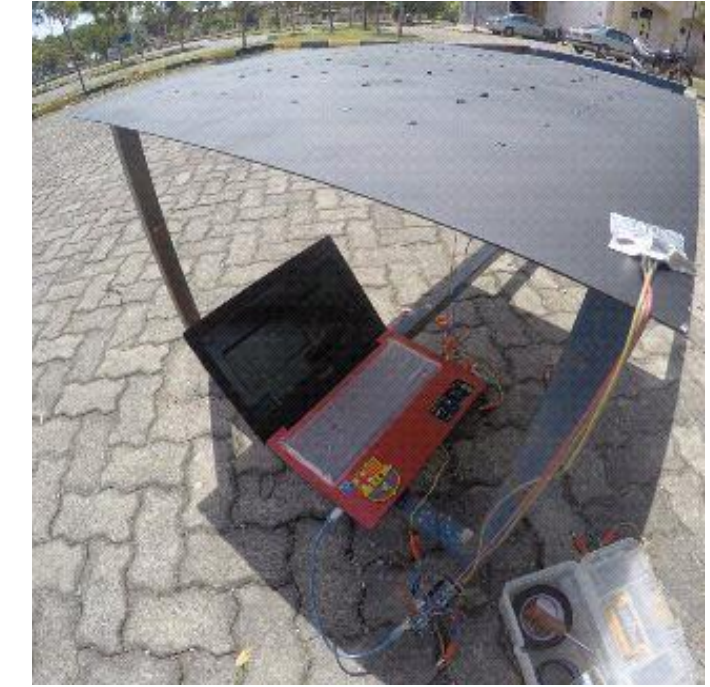

1. 5 TEG terhubung secara seri

Pada konfigurasi ini, output tegangan yang diperoleh masih sangat kecil. Hal ini dikarnakan suhu yang terukur pada kolektor berkisar antara $30-35^{\circ} \mathrm{C}$. dimana tegangan yang dihasilkan dapat dilihat pada tabel berikut.

Tabel 1. 5 TEG terhubung seri

\begin{tabular}{|c|c|c|c|}
\hline \multirow{2}{*}{$\begin{array}{c}\text { Tegangan } \\
(\mathrm{V} \mathrm{dc})\end{array}$} & \multicolumn{3}{|c|}{ Temperatur $\left({ }^{0} \mathrm{C}\right)$} \\
\cline { 2 - 4 } & 32,71 & 33,2 & 34,18 \\
\cline { 2 - 4 } & 0,11 & 0,13 & 0,16 \\
\hline
\end{tabular}

Pada tabel 1 diatas dapat dilihat bahwa pada suhu $32,71^{\circ} \mathrm{C}$ tegangan yang terukur sebesar $0,11 \mathrm{Vdc}$, dan tegangan ini akan naik seiring dengan naiknya suhu pada kolektor.

2. 12 TEG terhubung secara seri

Tidak terdapat kenaikan yang signifikan ketika 12 TEG dihubungkan secara seri, pada konfigurasi ini nilai tegangan yang diperoleh adalah 0,37 Vdc pada suhu 37,11 C.

Tabel 2. 12 TEG terhubung seri

\begin{tabular}{|c|c|c|c|}
\hline \multirow{2}{*}{$\begin{array}{c}\text { Tegangan } \\
(\mathrm{V} \mathrm{dc})\end{array}$} & \multicolumn{3}{|c|}{ Temperatur $\left({ }^{\circ} \mathrm{C}\right)$} \\
\cline { 2 - 4 } & 35,6 & 36,62 & 37,11 \\
\cline { 2 - 4 } & 0,29 & 0,33 & 0,37 \\
\hline
\end{tabular}

3. 20 TEG terhubung secara seri dan parallel. Pada konfigurasi ini 2 x 10 TEG terhubung secara seri kemudian dari dua baris TEG seri ( 10 seri) dihubungkan secara parallel.

Tabel 3. 20 TEG terhubung seri-paralel

\begin{tabular}{|c|c|c|c|}
\hline \multirow{2}{*}{$\begin{array}{c}\text { Tegangan } \\
(\mathrm{V} \mathrm{dc})\end{array}$} & \multicolumn{3}{|c|}{ Temperatur $\left({ }^{\circ} \mathrm{C}\right)$} \\
\cline { 2 - 4 } & 44,92 & 56,64 & 58,59 \\
\cline { 2 - 4 } & 3,89 & 4,51 & 5 \\
\hline
\end{tabular}

Tegangan yang terukur pada konfigurasi ini mencapai $5 \mathrm{Vdc}$ pada suhu $58,59^{\circ} \mathrm{C}$. 
Jenis plat yang digunakan juga mempengaruhi kecepatan dan panas maksimal dari kolektor panas matahari, berdasarkan percobaan yang dilakukan menggunakan tiga jenis plat yang berbeda yaitu Plat Alumunium, Plat Besi dan Plat Seng diperoleh data sebagai berikut.

Tabel 4. Kecepatan perubahan panas pada plat alumunium.

\begin{tabular}{|c|c|c|c|c|c|c|c|c|c|c|c|}
\hline \multirow{3}{*}{ Suhu } & \multicolumn{10}{|c|}{ Waktu (s) } \\
\cline { 2 - 14 } & 0 & 18 & 36 & 54 & 72 & 90 & 108 & 126 & 144 & 162 & 180 \\
\cline { 2 - 13 } & 28,32 & 28,8 & 29,79 & 30,76 & 32,23 & 34,18 & 36,13 & 38,09 & 40,04 & 41,02 & 42,48 \\
\hline
\end{tabular}

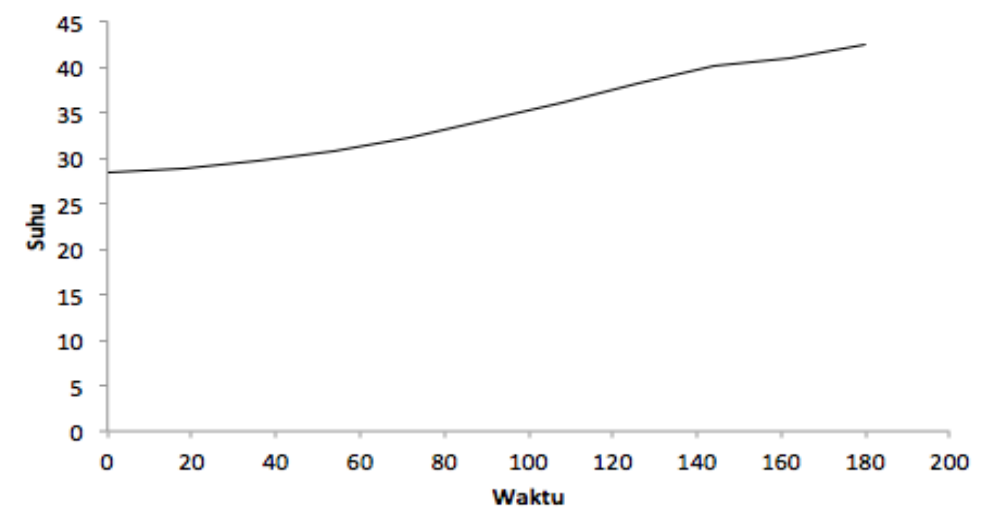

Gambar 7. Grafik hubungan perubahan suhu terhadap waktu.

Pengambilan data kecepatan penyerapan panas pada masing-masing plat dilakukan pada siang hari antara pukul 12.00 hingga 13.00, dimana kondisi cuaca disaat pengambilan data dalam kondisi cerah. Durasi pengambilan data, diambil dalam waktu yang sama yaitu 180 detik.
Pada gambar 7 terlihat bahwa pada plat alumunium, perubahan panas yang terjadi sangat cepat dan memiliki kecendrungan meningkat seiring dengan waktu. Suhu tertinggi pada detik ke 180 adalah $42,48^{0} \mathrm{C}$.

Tabel 5. Kecepatan perubahan panas pada plat besi

\begin{tabular}{|c|c|c|c|c|c|c|c|c|c|c|c|}
\hline \multirow{3}{*}{ Suhu } & \multicolumn{10}{|c|}{ Waktu (s) } \\
\cline { 2 - 14 } & 0 & 18 & 36 & 54 & 72 & 90 & 108 & 126 & 144 & 162 & 180 \\
\cline { 2 - 12 } & 27,83 & 27,34 & 27,34 & 26,86 & 26,86 & 26,86 & 26,86 & 27,34 & 27,83 & 27,83 & 27,83 \\
\hline
\end{tabular}

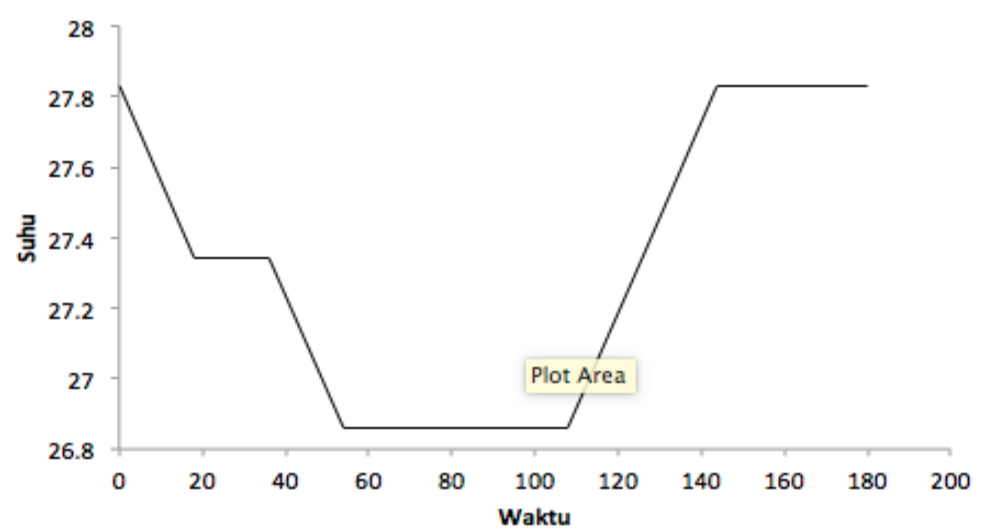

Gambar 8. Grafik hubungan perubahan suhu terhadap waktu.

Pada gambar 8 terlihat bahwa perubahan suhu yang terjadi pada plat besi berbeda pada plat alumunium. Pada plat besi terjadi penurunan suhu pada detik ke 20 menjadi $27,34^{\circ} \mathrm{C}$, dari suhu awal sebesar $27,83^{\circ}$ C. hal ini dikarnakan lambatnya plat besi untuk menyebarkan panas pada permukaannya. Hal ini terlihat dalam durasi waktu antara 0 hingga 180 detik tidak terjadi kenaikan suhu pada permukaan plat besi. 
Tabel 6. Kecepatan perubahan panas pada plat seng

\begin{tabular}{|c|c|c|c|c|c|c|c|c|c|c|c|}
\hline \multirow{3}{*}{ Suhu } & \multicolumn{10}{|c|}{ Waktu (s) } \\
\cline { 2 - 14 } & 0 & 18 & 36 & 54 & 72 & 90 & 108 & 126 & 144 & 162 & 180 \\
\cline { 2 - 13 } & 28,10 & 29,3 & 28,81 & 28,81 & 28,81 & 28,81 & 29,3 & 23,3 & 29,3 & 29,3 & 29,3 \\
\hline
\end{tabular}

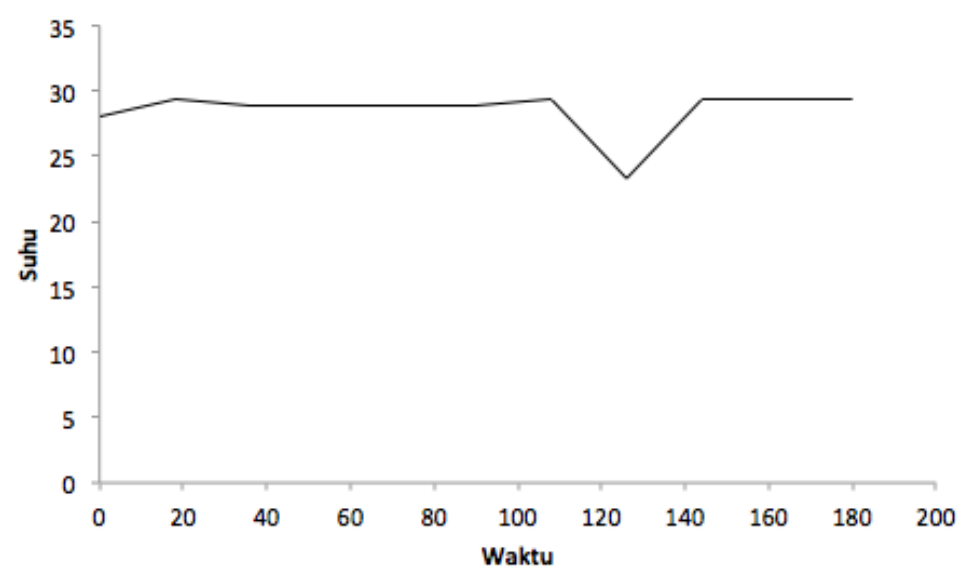

Gambar 9. Grafik hubungan perubahan suhu terhadap waktu plat seng.

Pada plat seng kondisi suhu permukaan plat memiliki kencendrungan konstan dalam waktu 180 detik, hal ini terlihat bahwa terdapat perbedaan yang sangat kecil terhadap kondisi suhu diawal yang sebesar $28,10^{\circ} \mathrm{C}$ menjadi $29,3^{0} \mathrm{C}$.

\section{Kesimpulan}

Dari penilitian yang dilakukan mengenai pemanfaatan panas matahari untuk menghasilkan energi listrik dapat diambil beberapa kesimpulan :

1. Konfigurasi optimal dari 20 TEG yang digunakan pada Heat Collector adalah 2 baris seri, dimana pada masing-masing baris terdiri dari 10 TEG yang dirangkai secara seri, dihubungkan secara parallel.

2. Pada konfigurasi ini diperoleh nilai tegangan sebesar $5 \mathrm{Vdc}$ pada suhu sebesar $58,59^{\circ} \mathrm{C}$.

3. Dari hasil percobaan terhadap 3 jenis plat yang digunakan pada collector, diperoleh data yang menunjukkan bahwa plat alumunium memiliki kecenderungan perubahan panas yang relative cepat apabila dibandingkan dengan plat besi dan plat seng.

\section{Daftar Pustaka}

[1] “Tentang Kepri." [Online]. Available: http://kepriprov.go.id/index.php/tentang-kepri. [Accessed: 29-Dec-2016].

[2] “b'right PLN Batam.” [Online]. Available: http://www.plnbatam.com/bright/content.asp?con tentid=417. [Accessed: 01-Mar-2017].
[3] L. E. Bell, "Cooling, Heating, Generating Power, and Recovering Waste Heat with Thermoelectric Systems," Science, vol. 321, no. 5895, p. 1457, Sep. 2008. 